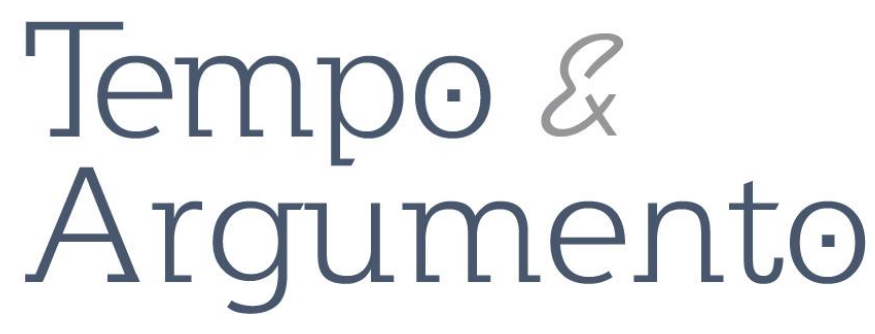

\title{
Leonel Brizola e os últimos anos de exílio
}

\begin{abstract}
Resumo
Após o golpe civil-militar de 1964, muitos políticos ligados ao governo deposto encontraram no exílio a chance de escapar das retaliações propostas pelo novo governo militar. Agindo assim, Leonel de Moura Brizola chegou ao Uruguai no início de maio de1964, dando início ao seu período de exílio. Este artigo, entretanto, tem por finalidade analisar os últimos anos de Brizola fora do país, período que vai dos últimos momentos da sua permanência no Uruguai, seguido pela breve passagem pelos Estados Unidos e o término do seu exílio em Lisboa, Portugal. Para atingir os objetivos propostos, buscou-se utilizar um conjunto de fontes que permitisse uma melhor análise da referida problemática - como documentos relativos à burocracia da repressão, imprensa e testemunhos - obedecendo o recorte cronológico proposto e inserindo a pesquisa na denominada História do Tempo Presente.
\end{abstract}

Palavras-chave: BRIZOLA, Leonel de Moura. 19222004. Exílio.

\author{
Maria Cláudia Moraes Leite \\ Doutoranda em História pela Universidade \\ Federal do Rio Grande do Sul (UFRGS). \\ Porto Alegre - RS - BRASIL \\ leite.mariaclau@gmail.com \\ orcid.org/0000-0002-5784-7080
}

\section{Para citar este artigo:}

LEITE, Maria Cláudia Moraes. Leonel Brizola e os últimos anos de exílio. Tempo e Argumento, Florianópolis, v. 11, n. 26, p. 353 -367, jan./abr. 2019. 


\title{
Leonel Brizola and the last years of exile
}

\begin{abstract}
After the civil-military coup of 1964, many politicians linked to the deposed government found in exile the chance to escape the retaliations proposed by the new military government. Acting like this, Leonel de Moura Brizola arrived in Uruguay in early May 1964, beginning his period of exile. This article, however, has the purpose of analyzing the last years of Brizola outside the country, a period that goes from the last moments of his stay in Uruguay, followed by the brief passage through the United States and the end of his exile in Lisbon, Portugal. To achieve the proposed objectives, we sought to use a set of sources wich would allow a better analysis of this problem - such as documents related to the bureaucracy of repression, press and testimonials obeying the proposed chronological and inserting the research in the called History of Present Time.
\end{abstract}

Keywords: BRIZOLA, Leonel de Moura. 1922-2004. Exile

\section{Introdução}

Exílio. Do latim exsilium, o que representa uma situação de desterro, deportação, degredo. Na complexa semântica do exílio há ainda a possibilidade de se acrescentar à reflexão os significados de apartar, arredar, afastar-se do convívio social. No período da ditadura militar brasileira ${ }^{1}$, o exílio foi o caminho encontrado por inúmeras pessoas que

\footnotetext{
${ }^{1}$ Utilizamos as expressões golpe civil-militar e ditadura militar de acordo com a conceituação do historiador Carlos Fico. Segundo o autor, "Os estudiosos do golpe de 1964 e do período histórico que se seguiu têm insistido em um ponto: não deveríamos usar as expressões 'golpe militar' e 'ditadura militar', pois seriam mais corretas as designações de golpe e ditadura 'civil militar'. A preocupação é louvável porque tem em vista justamente o fato de que houve apoio civil ao golpe e ao regime. Eu sustentaria, no entanto, um ponto de vista um pouco diferente: não é o apoio político que determina a natureza dos eventos da história, mas a efetiva participação dos agentes históricos em sua configuração. Nesse sentido, é correto designarmos o golpe de Estado de 1964 como civil-militar: além do apoio de boa parte da sociedade, ele foi efetivamente dado também por civis. Governadores, parlamentares, lideranças civis brasileiras - e até o governo dos Estados Unidos da América - foram conspiradores e deflagradores efetivos, tendo papel ativo como estrategistas. Entretanto, o regime subsequente foi eminentemente militar e muitos civis proeminentes que deram o golpe foram logo afastados pelos militares justamente porque punham em risco o seu mando. É verdade que houve o apoio de parte da sociedade também à ditadura posterior ao golpe - como ocorreu durante o período de grande crescimento da economia conhecido como 'milagre brasileiro' -, mas, como disse antes, não me parece que apenas o apoio político defina a natureza de um acontecimento, sendo possivelmente mais acertado considerar a atuação dos sujeitos históricos em sua efetivação. Por isso, admito como correta a expressão 'golpe civil-militar', mas o que veio depois foi uma ditadura indiscutivelmente militar” (FICO, 2014, p. 9-10).
} 
não puderam viver sob um regime de exceção. No entanto, ao longo da história, o exílio foi utilizado como um mecanismo que servia para afastar pessoas que de alguma forma perturbavam o status quo. Também foi utilizado como um meio de povoar regiões desabitadas nas margens dos impérios. Com a desintegração do império espanhol nas Américas e a subsequente disputa pelo poder entre as elites políticas dos novos países independentes, se abre um campo de disputa pelo poder e o exílio assume uma tonalidade especificamente política na América Latina. As possibilidades de lutas abertas pela independência proporcionaram duas situações que não interessavam às elites: o extermínio do oponente, que poderia gerar infinitas represálias; ou a mobilização das camadas mais baixas com o intuito de requerer o poder (RONIGER; SZNAJDER, 2008).

Mediante tal impasse, que não apresentava uma solução adequada para a conservação da hegemonia política das elites que estavam no poder, o uso do exílio foi visto como solução intermediária e como um mecanismo institucionalizado de controle político, uma vez que deslocava seus opositores para outros territórios. O exílio, todavia, constituía-se numa pena significativa, pois, em virtude das condições de comunicação da época, resultava na ruptura com os antigos contatos sociais, na perda do protagonismo político e nas fontes de sustento (RONIGER, 2010). Todos os países da América Latina, na análise de Luis Roniger (2011), incorporaram o exílio como uma prática política importante, apesar das trajetórias institucionais diferentes - e principalmente a partir da década de 1960, com o advento das ditaduras militares que tomaram conta dos países do cone sul-latino-americano.

Essa experiência exílica que, segundo Yankelewich (2011, p. 14), alcançou um caráter massivo deve ser compreendida como um "processo coletivo, mas desenvolvido a partir do somatório de ações individuais". Corroborando com a tese do autor, Roniger (2011, p. 33) argumenta que foi justamente o "caráter forçado e massivo do exílio que levou a tomar consciência da sua profundidade histórica, funcionalidade repressiva e diversidade contextual”. A partir daí, observou-se o exílio como um mecanismo de exclusão política institucionalizada na América Latina dos anos 1960 e 1970.

Logo após o golpe de 1964 no Brasil, uma série de políticos ligados ao governo deposto ou que eram vistos como opositores ao novo regime, dentre eles Leonel Brizola, 
encontravam-se imersos num contexto de suspensão dos direitos políticos e cassação de mandatos. Grande parte desses políticos e intelectuais escolheu o exílio como destino no pós-golpe, uma vez que a dificuldade em permanecer no país era cada vez maior. Outros, inclusive, viram no exílio a única opção de sobrevivência. Leonel Brizola, após um mês clandestino no Brasil, partiu para o exílio no Uruguai - local no qual permaneceu por 13 anos. Entretanto, serão tratados neste texto apenas os anos finais de exílio que correspondem aos últimos momentos no Uruguai, à passagem pelos Estados Unidos e sua finalização em Lisboa, Portugal.

\section{Os últimos anos de exílio}

Os últimos anos de Leonel Brizola no exílio foram marcados por acontecimentos que o fizeram buscar outros caminhos, novos horizontes. O seu exílio sempre foi cercado de peculiaridades jamais vistas em outros decorrentes das ditaduras militares do Cone Sul da América Latina. O início do asilo político de Brizola foi marcado pelo seu confinamento em Atlântida - Uruguai, no ano de 1965, local onde ficou até 1971. Posteriormente, fixou residência na Rambla Armênia, em Montevidéu, e numa fazenda em Villa Carmem, no departamento de Durazno, dedicando-se à criação de ovelhas e à agricultura. Foi um período de calmaria nas atividades políticas desenvolvidas por Brizola. Todavia, foi nesse momento que a ditadura uruguaia, pressionada pela ditadura brasileira, resolveu expulsar Brizola do país, acrescentando mais dramaticidade ao exílio do político.

Antes, porém, de comentar a atitude do governo uruguaio, faz-se necessário registrar um importante momento do exílio de Brizola, ocorrido em 1976: a sua reaproximação com João Goulart, após 11 anos de rompimento por divergências políticas. O encontro teria acontecido quando Jango, já exilado na Argentina, foi a Montevidéu e aproveitou para visitar a irmã e o cunhado. Os dois líderes trabalhistas conversaram sozinhos por mais de duas horas. No fundo, apesar das divergências, eles sempre se estimaram. Jango, na oportunidade, contou ao cunhado que não confiava no MDB para abreviar os seus dias de exílio. O ex-presidente achava que, "se dependesse da vontade dos líderes do partido, criado pelo regime militar, ele e Brizola, principalmente, morreriam 
no exílio, e políticos ligados ao MDB estariam à vontade para fazer discursos laudatórios nos seus enterros" (BRAGA, 2004, p. 101). Entre outros assuntos, falaram também sobre as ameaças que sofriam - os dois haviam sido avisados por Miguel Arraes dos perigos que corriam, inclusive da possibilidade de atentados, com o início dos trabalhos da Operação Condor $^{2}$. Brizola, no entanto, não havia dado créditos ao aviso, pois acreditava que poderia haver troca de informações entre dois países, mas não associações para praticar atentados. Jorge Ferreira relata que,

recusando-se a viver em função de ameaças, Brizola apenas observava algumas medidas de segurança, como não sair de casa sempre à mesma hora, evitando qualquer tipo de regularidade, embora, com autorização do governo uruguaio, andasse armado. (FERREIRA, 2011, p. 652)

Brizola passava os dias tranquilo, na fazenda de Durazno ou no apartamento de Montevidéu. "Fazia compras do cotidiano e gostava de conversar com as pessoas nas ruas e nos estabelecimentos comerciais, num espanhol caprichado. Todos se referiam a ele como el ingeniero Brizola" (BRAGA, 2004, p. 94). Durante o exílio, o político teve muitas decepções, mas também vivenciou momentos de alegria face à solidariedade dos seus companheiros. Conforme coloca Braga,

alguns participavam do cotidiano do líder trabalhista exilado, outros o visitavam frequentemente, levando-lhe pequenos presentes de valor inestimável, como carteiras de cigarro Hollywood, sem filtro, livros, fitas cassete e até aipim e rapadura. E havia ainda os amigos fiéis que ficaram no Brasil, que se uniam num mutirão de auxílio a Brizola, ajudando-o a resolver problemas de ordem pessoal como o encaminhamento de negócios, cobranças e atualizações de documentos.

\footnotetext{
2 "Articulados entre si, os esquemas de segurança do Brasil, do Uruguai, da Argentina, do Paraguai, da Bolívia e do Chile, coordenados por grupos de extrema direita, deram início à Operação Condor. Versões mais seguras garantem que os generais chilenos responsáveis pelo serviço secreto do país, a Dina, propuseram o acordo aos outros países, com o aval do governo dos Estados Unidos. Em 29 de outubro de 1975, ocorreu a primeira reunião de trabalho, convocada pelo coronel chileno Manoel Contreras. Inicialmente, ficou estabelecido que os diversos serviços de segurança associados formariam um banco de dados e um arquivo centralizado com fichas dos suspeitos. Desse modo, informações sobre opositores, exilados e grupos esquerdistas seriam trocadas. A repatriação de um exilado de um país para outro não seguiria os caminhos da Justiça e da diplomacia, mas ocorreria de maneira clandestina. A fase seguinte da Operação implicaria sequestros, atentados e assassinatos. As forças de segurança dos seis países poderiam executar qualquer opositor a um dos regimes militares, independentemente de sua nacionalidade e do território nacional em que estivesse exilado. Outras informações igualmente garantem que, mais tarde, passaram a ter liberdade para eliminar opositores em países que não fizessem parte do acordo, na Europa ou nos Estados Unidos" (FERREIRA, 2011, p. 650-652).
} 
Admirável por sua fidelidade, por exemplo, foi Danilo Groff, preso em várias ocasiões por estar transportando material considerado subversivo. Danilo Groff e João Guaragna devem constar, obrigatoriamente, de uma relação que incluísse os nomes dos grandes amigos e companheiros de Brizola durante os anos do seu exílio no Uruguai. Não lhe faltou, nos momentos de maior angústia, a mão amiga estendida na troca de uma cuia de chimarrão. (BRAGA, 2004, p. 94)

Não faltou também a Brizola boas relações com políticos uruguaios defensores da legalidade e contrários ao golpe sofrido no Brasil. Contudo, em 1977, quando recebeu o decreto que o expulsava do país, a conjuntura política era completamente diferente daquela que permitiu a sua defesa na Camara de Representantes quando do seu confinamento em Atlântida, em 1965. Num cenário de ditaduras militares afins, não foi difícil para o Brasil conseguir o tão desejado desterro de Brizola. Fora assim decretado o fim de 13 anos de asilo político no Uruguai. No dia 13 de setembro de 1977, o documento $\mathrm{n}^{\circ}$ 687, do Ministério das Relações Exteriores do Uruguai, deu conta da seguinte resolução:

VISTO: la Resolución del Poder Ejecutivo de fecha 2 de junio de 1964, por la que se declaro asilado político al ciudadano brasileño, Señor Leonel Brizola;

ATENTO: a la información transmitida por el Ministerio del Interior con fecha 8 del corriente señalando que el referido asilado no há guardado las obligaciones inherentes a su condición de tal;

\section{EL PRESIDENTE DE LA REPUBLICA \\ RESUELVE:}

$1^{\circ}$ - Revócase la Resolución de fecha 2 de junio de 1964, por la que se declaro al asilado político al ciudadano brasileño, Señor Leonel Brizola. $2^{\circ}$ - Comuníquese, anótese, notifíquese al interessado que deberá hacer abandono del território nacional y archívese.

(Fdo.:) MENDEZ ALEJANDRO ROVIRA ${ }^{3}$

Brizola já havia recebido a acusação de ter infringido as regras de asilo político diversas vezes desde que chegara ao Uruguai. Mas a notícia da expulsão, sem qualquer aviso prévio ou circunstância aparente que o levasse a tomar certas precauções, pegou Brizola de surpresa. Não havia razão tangível, pessoal ou política, que justificasse a

\footnotetext{
3 Archivo Administrativo del Ministério de Relaciones Exteriores de la República Oriental del Uruguay.
} Correspondência $n^{\circ} 687$. Montevideo, 13 de setiembre de 1977. 
medida tomada. Todavia, Brizola não tinha dúvidas de que a ordem partira do Brasil. De acordo com Leite Filho,

o próprio Palácio do Planalto, através do porta-voz interino João Madeira, chegou a declarar que "o Governo brasileiro tinha conhecimento prévio de que o Uruguai iria suspender o asilo político de Leonel Brizola". (LEITE FILHO, 2008, p. 341)

O político tentava entender o porquê da sua expulsão, já que havia alguns anos que não atuava ostensivamente em relação à política brasileira. Soube, anos mais tarde, que a revogação de sua condição de asilado, aparentemente, foi provocada pela disputa interna entre o Ministro da Guerra do Brasil, general Sílvio Frota, e o presidente Ernesto Geisel. Frota queria impor o próprio nome como candidato à sucessão presidencial; Geisel, por sua vez, apoiava João Batista Figueiredo, outro general. Para conseguir o seu intento, Frota articulava um golpe no estilo do que, em 1968, derrubara o vice-presidente Pedro Aleixo, civil que assumiria o poder em face do impedimento do presidente Arthur da Costa e Silva. Aleixo acabou surpreendido pelos generais que colocaram em seu lugar uma junta militar constituída pelos três ministros militares de Costa e Silva: general Aurélio Tavares, do Exército; almirante Augusto Rademaker, da Marinha; e brigadeiro Márcio Melo, da Aeronáutica (LEITE FILHO, 2008). Todavia, para que o golpe fosse seguro, Frota necessitava que a região sul, local onde se situava o III Exército, ficasse livre da presença de Brizola, uma vez que o político, residindo tão perto da fronteira, possivelmente retornaria ao Brasil para reeditar a Campanha da Legalidade, o que desestabilizaria ou até mesmo derrubaria o futuro regime frotista. Para Leite Filho (2008, p. 342), "essa seria a razão intrínseca do grupo de Frota, ao exigir, extemporaneamente, a expulsão de Brizola do país vizinho. Geisel teve de concedê-la e os militares uruguaios, de executá-la". A disputa entre os grupos de Geisel e Frota acabou praticamente um mês após o decreto de expulsão de Brizola, quando o presidente, num golpe de força, demitiu Frota do Ministério e liquidou com a sua pretensão à presidência.

Após tomar conhecimento do decreto que o expulsava, Brizola teve cinco dias para abandonar o país. Segundo Neiva Moreira, 
Brizola, sem muitas alternativas, mas com grande capacidade política, percebeu que se lhe afigurava uma oportunidade de testar a política de direitos humanos implementada pelo Presidente dos Estados Unidos, Jimmy Carter (MOREIRA, 1989, p. 104)

O pedido de visto que Brizola fez na Embaixada dos Estados Unidos esbarrava num entrave burocrático: o fato de os Estados Unidos não serem signatários de convenção de asilo com o Uruguai ou com qualquer outro país. Havia também outra tradição inibitória, que era a de não conceder asilo fora do território americano. Segundo Leite Filho,

os milhares de asilados lá residentes, sobretudo os dissidentes de países comunistas, como os da ex-União Soviética e de Cuba, encaminharam suas solicitações depois de penetrarem em solo americano, muitos deles em viagens oficiais patrocinadas pelos próprios governos. Havia, porém, um único precedente similar ao caso de Brizola: era o do cardeal primaz da Hungria, Joseph Mindzenty, em 1971, um preso político havia mais de 23 anos no próprio país, e que depois foi morar em Viena, na Áustria. Quanto aos brasileiros, somente o ex-presidente Washington Luis e 0 socialista baiano João Mangabeira, que chegou a ser ministro da Justiça de João Goulart, haviam morado em Nova lorque. Eles também não tinham obtido asilo e sim um visto temporário, que lhes garantiu a permanência no país, pois eram dissidentes do regime brasileiro de Vargas. (LEITE FILHO, 2008, p. 345)

Entretanto, Jimmy Carter estava comprometido em fazer valer sua política de descompressão na América Latina, arrasada por ditaduras militares que tiveram o apoio dos Estados Unidos. Dessa forma, “o Presidente passou por cima de todos os empecilhos burocráticos, políticos e mesmo legais, mandando conceder o visto de Brizola, num prazo recorde de 48 horas" (LEITE FILHO, 2008, p. 345). A autorização da ida de Brizola para os Estados Unidos foi recebida como um gesto de hostilidade às ditaduras militares do Brasil e do Uruguai. Ainda que discricionários no plano interno, esses regimes se viram impotentes frente à decisão norte-americana. Ainda assim, as ditaduras brasileira e uruguaia tentaram obrigar Brizola a passar por alguns constrangimentos, como a decretação de sua prisão domiciliar, justamente no dia em que foi divulgada a decisão estadunidense. 
No dia 20 de setembro, às 22h3omin, Brizola, juntamente com sua família, embarcou no Aeroporto de Carrasco, Montevidéu, com destino a Buenos Aires, onde ficaram por uma noite, antes de seguirem viagem para os Estados Unidos. A Argentina, que vivia debaixo da sombria ditadura de Jorge Rafael Videla, reservou ainda uma desagradável surpresa ao ex-governador quando destinou o Hotel Liberty como local para que passasse a noite. Vários casos de sequestros e assassinatos políticos a mando da ditadura e da Operação Condor haviam ocorrido no hotel, como o caso dos parlamentares uruguaios Zelmar Michelini, senador, e Hector Gutiérrez Ruiz, deputado, que tinham sido arrancados à força de seus apartamentos no Liberty e encontrados mortos logo em seguida. Os temores de Brizola de que algo acontecesse a ele ou a alguém da sua família só foram dissipados quando os jornalistas que foram entrevistá-lo no Aeroporto de Ezeiza se dispuseram a fazer uma vigília em frente ao seu apartamento (LEITE FILHO, 2008).

Nas duas entrevistas que concedeu em Buenos Aires, Brizola afirmou que não havia desenvolvido nenhuma atividade que configurasse violação às normas de asilo. Questionado sobre se exerceria atividade política nos Estados Unidos, admitiu que voltaria a ter algum tipo de ação. Insistiu, contudo, em dizer que não tinha nenhum sentimento de vingança ou revanchismo. Assim, Brizola embarcou para Nova York. Nas palavras de Moniz Bandeira (1979, p. 105), “o Governo do Uruguai, ao expulsá-lo do seu território, abriu-lhe as portas do mundo, libertou-o, reintegrando-o, por mais paradoxal que isto pareça, na política brasileira", possibilitando contatos com líderes de projeção internacional. Brizola poderia, então, seguir os conselhos dos políticos do MDB, que insistiam para que ele efetuasse viagens pelo exterior propagandeando a anistia brasileira.

Nos Estados Unidos, ele viu sua rotina mudar bruscamente. Deixou de lado a vida tranquila de fazendeiro e entregou-se à vida política, retomada com garra. Em entrevista concedida ainda no Hotel Liberty, em Buenos Aires, Brizola fala sobre a mudança que estava ocorrendo na sua vida: “Eu já havia praticamente largado (tudo), mas vejam como é isso, me agarraram pelos cabelos. Não tenho planos, mas como disse um poeta espanhol: Caminos, caminos, no hay. Hay que hacerlos" (LEITE FILHO, 2008, p. 350). Depois 
do fracasso da insurreição de $1967^{4}$, o ex-governador havia praticamente se recolhido em Durazno. Embora ainda recebesse a visita de muitas pessoas do Brasil, principalmente membros do MDB, evitava expor-se. No entanto, a saída drástica do Uruguai o colocou novamente como uma figura de destaque na política, ainda mais naquele momento em que os militares, a despeito das suas divisões internas e de suas indefinições, conforme aborda Américo Freire,

acenavam com medidas que deveriam acelerar o processo de distensão política, tais como a edição de uma nova Lei de Segurança Nacional, a aprovação de uma anistia parcial, além da extinção do sistema bipartidário. Em razão disso, tornou-se intensa a movimentação dos atores políticos no sentido de construir estratégias para os novos tempos que estavam por vir. Para alguns, por exemplo, era a hora de resistir à imposição da agenda governamental mantendo-se na frente oposicionista legal - o MDB, depois PMDB. Para outros, era o momento de uma maior afirmação político-ideológica por meio da criação de um partido socialista que agrupasse diferentes grupos e facções de esquerda. (FREIRE, 2010, p. 38-39)

É neste contexto de efervescência política que, em janeiro de 1978, Brizola aceitou o convite do primeiro-ministro português, Mario Soares, e se mudou para Lisboa após uma série de viagens pelos países da Europa. Após um longo exílio no Uruguai, o exgovernador encontrava-se em um momento favorável de sua carreira política: nas palavras de Américo Freire (2010, p. 38), Brizola "já deixara de lado a sua vestimenta de revolucionário para se apresentar como líder moderno e inconteste do trabalhismo brasileiro". Sua grande entrada na política europeia, no entanto, ocorreu em fevereiro, segundo Leite Filho, durante a reunião da Internacional em Hamburgo, Alemanha:

Lá, é apresentado aos líderes socialistas europeus, à frente o chanceler da Alemanha Ocidental e então presidente da Internacional, Willy Brandt. Conhece igualmente, François Miterrand, da França, Olaf Palm, da Suécia; e Felipe Gonzales, da Espanha, este também egresso do exílio imposto pelo franquismo.

Ainda em fevereiro, ele viaja à França, onde é recebido na sede do Partido Socialista Francês, quando assina um comunicado conjunto com o PSF, no qual os socialistas franceses se comprometem a estreitar os laços com "o movimento de opinião representado por Brizola", no propósito de apoiar "qualquer processo de democratização autêntica do Brasil”. (LEITE FILHO, 2008, p. 355)

\footnotetext{
${ }^{4}$ É a insurreição denominada de Guerrilha de Caparaó, insurgência armada contra o regime militar brasileiro localizado na serra de Caparaó e que contava com Leonel Brizola como uma de suas lideranças.
} 
A aproximação com aquelas lideranças foi facilitada pelos militantes do Comitê de Anistia de Portugal, que tinha à frente Maurício Paiva, Domingos Fernandes e Almir Ferreira Duton, todos ex-guerrilheiros que alcançaram a liberdade no Brasil ao serem trocados por embaixadores sequestrados. Esses nomes foram cruciais no auxílio a Brizola, neste período em que o político buscava levar adiante o seu projeto de reconstrução do trabalhismo.

O grande sonho de Brizola era reorganizar o PTB, ampliando e renovando os quadros existentes antes do golpe de 1964, com ênfase em sua evolução a caminho do socialismo. Seria a retomada de um projeto interrompido pela ditadura. Mas seria também, conforme aborda Braga (2004, p. 104), "a forma de se fazer justiça a uma agremiação política que, em 1964, teve em suas lideranças maiores as principais vítimas das cassações, das punições, dos exílios e dos banimentos impostos pelos militares". O debate em torno da refundação do partido se realizou em diversos encontros, no Brasil e no exterior. O mais importante, pela sua dimensão e representação, ficou conhecido como Congresso de Lisboa e aconteceu entre os dias 15 e 17 de junho de 1979, na sede do Partido Socialista Português, com a presença de 1500 pessoas:

Lá estiveram reunidos, para discutir o futuro dos movimentos sociais e políticos do Brasil, líderes de esquerda das mais variadas tendências, juntamente com exilados brasileiros procedentes de diversos países. A abertura do encontro coube ao primeiro-ministro português, Mario Soares. E o que se observou na realização dos trabalhos foi um clima de muita união, visando à construção de um novo projeto trabalhista no Brasil. (BRAGA, 2004, p. 105)

Entre os documentos elaborados no Congresso, a Carta de Lisboa foi a de maior repercussão, tornando-se um guia para a ação política dos seguidores de Brizola. 0 documento enfatizava a urgência em organizar, com o apoio do povo brasileiro, um partido verdadeiramente nacional, popular e democrático. Um partido de massas e não apenas um representante da classe operária - seria orientado para os trabalhadores, mas também para os desprivilegiados em geral (VAINFAS, 2007).

A realização do Congresso de Lisboa coincidiu com os últimos "retoques" que o governo do general Figueiredo fez no projeto da anistia, permitindo a volta dos exilados à 
pátria. O país vivia um clima de ebulição decorrente das atividades dos movimentos políticos e sociais, que se agitavam e se faziam ouvir nas diversas instâncias do poder. Neste contexto, o retorno de Brizola à política brasileira e as diversas possibilidades de atuação no país eram temas recorrentes na embaixada uruguaia. O general Eduardo $M$. Zubía, embaixador do Uruguai no Brasil, justifica a preocupação com as futuras atitudes do político:

Debido a ser el Estado de Río Grande del Sur limítrofe con nuestro país, a su población, a sus dimensiones, a la influencia mutua que existen entre ambos, considero de suma importancia seguir atentamente el proceso político en Río Grande del Sur ya que su destino está intimamente ligado al nuestro país 5 .

Além disso, o documento em questão faz também observações sobre a reestruturação de um novo Partido Trabalhista Brasileiro ao abordar a reportagem do Correio Braziliense de $1^{\circ}$ de julho de 1979, o qual anuncia que a maioria do MDB gaúcho havia aderido a Brizola. Conforme a notícia:

Treze dos 18 deputados federais do MDB do Rio Grande do Sul já decidiram aderir ao PTB de Leonel Brizola, mas só deverão anunciar o fato depois de um encontro que o senador Pedro Simon, presidente do diretório regional, terá com o ex-governador gaúcho e se até lá ficar evidente a extinção dos demais partidos.

[...] Onze dos 13 deputados, contudo, ainda estão fazendo, sem muita convicção, um último esforço para salvar o MDB e, por isso, participaram ativamente da última reunião do diretório nacional do partido, realizado na quinta-feira. $O$ deputado Alceu Colares, que está à frente desse movimento, advertiu que o MDB ou o que restar dele com a extinção, só poderá sobreviver se se transformar num partido de massas, com um programa arrojado, "do tipo daquele elaborado pelo novo PTB", como disse. Informalmente, no entanto, Colares manifesta a opinião de que, se os partidos forem mesmo extintos, "não haverá outra saída para o MDB senão engrossar as fileiras do PTB, que tem sua linha de princípio e de ação tão ou mais avançada quanto a dos autênticos ${ }^{6}$.

A organização de um PTB forte e dominante no Rio Grande do Sul e, principalmente, dirigido por Brizola, preocupava o governo do Uruguai, que considerava o político um inimigo do seu então processo político - a ditadura militar. A sua presença

\footnotetext{
${ }^{5}$ Archivo Administrativo del Ministério de Relaciones Exteriores de la República Oriental del Uruguay. Correspondência ${ }^{\circ}$ 14010. Montevideo, 5 de julio de 1979.

${ }^{6}$ Correio Braziliense, Brasilia, $1^{\circ} / 7 / 1979$.
} 
no Rio Grande do Sul poderia dificultar o relacionamento existente entre o estado gaúcho e a ditadura em questão7. Percebe-se, dessa forma, que mesmo após a sua saída do Uruguai, Brizola ainda continuou sendo alvo da vigilância da repressão daquele país, que sempre o considerou uma ameaça política às pretensões ditatoriais de qualquer país da América Latina.

\section{Considerações finais}

Foi neste contexto de incertezas quanto à recriação do PTB que Brizola, finalmente, retornou ao Brasil com a promulgação da anistia. Ao contrário dos inúmeros exilados que desembarcavam no Aeroporto do Galeão, no Rio de Janeiro, o exgovernador preferiu reingressar no Brasil por São Borja, pequena cidade gaúcha terra dos presidentes Getúlio Vargas e João Goulart. Local cheio de simbolismo, assim como a data prevista para a sua chegada - 7 de setembro, dia da independência do país. Em Assunção, no Paraguai, Brizola realizou a última escala do voo que o trazia de Nova York e, de acordo com Leite Filho, o político defrontou-se com a opressão das ditaduras que ainda dominavam a América Latina:

Um enorme aparato de segurança o aguardava no Aeroporto Guarany, sob as ordens do ministro do Interior, Sabino Montanaro, que foi cumprimentá-lo pessoalmente, em nome do presidente, o general Alfredo Stroessner. Montanaro estava acompanhado do chefe da Casa Militar, coronel José Rabito e outras autoridades.

A polícia de Montanaro, que manteve afastados os militantes brizolistas vindos do Brasil para saudar seu líder, ainda proibiu que os jornalistas se aproximassem: "As declarações ficam para Foz do Iguaçu”, decretou o ministro. O Presidente Stroessner, na realidade, tinha feito restrições àquele pouso do ilustre exilado em Assunção: "Olha, eu sou amigo de seu pai, do Brizola, não", disse ele ao filho de Jango, João Vicente Goulart, que lhe foi pedir autorização para o desembarque do tio Leonel, no país. (LEITE FILHO, 2008, p. 371)

Na capital paraguaia, Brizola foi recebido pelo filho, João Vicente Brizola, pelo senador Pedro Simon, pelo ex-deputado Wilson Vargas, pelo ex-prefeito de Porto Alegre, Sereno Chaise e pelo filho de João Goulart, João Vicente Goulart. Seguiram todos para

\footnotetext{
7 Archivo Administrativo del Ministério de Relaciones Exteriores de la República Oriental del Uruguay. Correspondência $n^{\circ} 14010$. Montevideo, 5 de julio de 1979.
} 
Foz do Iguaçu, de onde partiram para São Borja nas primeiras horas do dia seguinte no avião de propriedade de João Vicente Goulart e pilotado por Maneco Leães, o mesmo piloto que havia conduzido Brizola para o exílio no Uruguai 15 anos antes (LEITE FILHO, 2008).

Às onze horas da manhã, com uma hora e meia de atraso, Brizola chegava a São Borja onde uma pequena multidão havia invadido a pista e o esperava na tentativa de abraçá-lo ou apenas tocá-lo. “Um dos populares ainda conseguiu entregar-lhe uma cuia de chimarrão, que as câmeras dos 150 jornalistas presentes puderam registrar como uma prova indelével de que Brizola tinha realmente voltado" (LEITE FILHO, 2008, p. 372).

Brizola seguiu para o cemitério, local onde fez o primeiro pronunciamento no país. Diante do túmulo de Getúlio Vargas, o político, contrariando o seu hábito de falar de improviso, leu um discurso escrito cuidadosamente nos seus últimos dias de exílio, carregado de emoção e sentimento histórico. Quinze anos após sua saída, Leonel de Moura Brizola enfim retornava ao Brasil. Era o reencontro tão esperado entre o político e o povo, entre o passado e o futuro que se tornava presente.

\section{Referências}

BANDEIRA, Luiz Alberto Moniz. Brizola e o trabalhismo. Rio de Janeiro: Civilização Brasileira, 1979.

BRAGA, Kenny et al. (Coords.). Perfis parlamentares. Leonel Brizola: perfil, discursos e depoimentos (1922-2004). Porto Alegre: Assembleia Legislativa do RS, 2004.

FERREIRA, Jorge. João Goulart: uma biografia. Rio de Janeiro: Civilização Brasileira, 2011.

FICO, Carlos. O golpe de 1964: momentos decisivos. Rio de Janeiro: Editora FGV, 2014. 
FREIRE, Américo. Ecos da Estação Lisboa. O exílio das esquerdas brasileiras em Portugal. Sociologia, Problemas e Práticas, n. 64, 2010.

LEITE FILHO, FC. El Caudillo Leonel Brizola: um perfil biográfico. São Paulo: Aquariana, 2008.

MOREIRA, Neiva. O pilão da madrugada. Um depoimento a José Louzeiro. Rio de Janeiro: Terceiro Mundo, 1989.

RONIGER, Luis; SZNAJDER. Antecedentes coloniales del exílio político y su proyección en el siglo XIX. Estudios Interdisciplinaros de America Latina y el Caribe, v. 18, n. 2, p. 31-51, 2008.

RONIGER, Luis. Exílio massivo, inclusão e exclusão política no século XX. Revista de Ciências Sociais, Rio de Janeiro, v. 53, n. 1, 2010, p. 91-123.

RONIGER, Luis. Reflexões sobre o exílio como tema de investigação: avanços teóricos e desafios. In: QUADRAT, Samantha Viz. Caminhos cruzados: história e memória dos exílios latino-americanos. Rio de Janeiro: Editora FGV, 2011.

VAINFAS, Ronaldo. A luz própria de Leonel Brizola. In: FERREIRA, Jorge; AARÃO REIS, Daniel (Orgs.). As esquerdas no Brasil: revolução e democracia. (1964...). v. 3. Rio de Janeiro: Civilização Brasileira, 2007. 